\title{
土壤含水量的热惯贯模型及其应用
}

\author{
张不华 \\ (中国科学院地理研究所, 北京 100101)
}

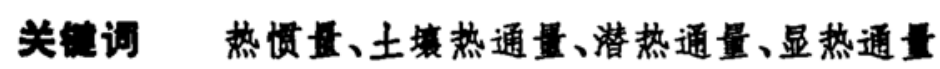

土壤含水量的信息在农业、水利、气候等方面的作用是不言而喻的. 然而土堆水分含量的 区域分布非常不均匀. 常规的点测量方法既费时间又没有代表性. 遥感方法在估算区域土壤 含水量分布方面有用武之地. 特别是热红外波段的热惯量遥感是一种现实而有效的方法 ${ }^{(1-4)}$.

热惯量信息是由土壤热通量中获取的,土壤热通量只是地表热量平衡方程中的一部分.净 辐射通量另一部分消耗于显热与潜热输送. 因此要提高热惯量遥感精度, 除尽可能精确估算 净辐射通量外，还要排除显热、潜热输送的干扰. 国外已在这方面研究取得进展 ${ }^{[5,6]}$, 但这问题 尚末最终解决. 本文在作者以前工作基础上提出了一个现实的克服显热、潜热输送干扰的热 掼量模式 ${ }^{(7-9)}$, 并在广西全州的热红外遥感试验加以估算精度验证。

\section{一、模式 这}

一维土壤热传导方程为

$$
\begin{gathered}
\frac{\partial T(z, t)}{\partial t}-K \frac{\partial^{2} T(z t)}{\partial z^{2}}, \\
K=\left(\frac{P}{C_{s} \rho_{s}}\right)^{2} .
\end{gathered}
$$

地表热照平衖方程有

$$
\begin{gathered}
R_{n}-H+L E+G, \\
T-\sum_{k=0}\left(A_{k} \cos \omega_{k} t+B_{k} \sin \omega_{k} t\right) .
\end{gathered}
$$

由(1)、(2)、(3)、(4)式可得每个象元点的热惯量

$$
P_{i}=\frac{\sum_{i=t_{1}}^{t_{3}}\left(R_{* i i}-H_{i j}-L E_{i i}\right) \cdot \Delta i}{\sqrt{\left(t_{2}-t_{1}\right)}\left(T_{0 i 2}-T_{0 i 1}\right)},
$$

式中 $T$ 是温度变量, $t$ 是时间变量, $K$ 是热扩散率, $P$ 是热惯量, $C$, 是土壤定压比热, $\rho_{s}$ 是土壤 密度, $G$ 是土壤热通量, $R$, 是净辐射通量, $H$ 是显热通量, $L E$ 是潜热通量, $\Delta i$ 是时间间隔, $i$ 是时段序号, $i$ 是象元点序号, $t_{1} 、 t_{2}$ 为计算热惯量的起始与终了时刻, $T_{02}, T_{01}$ 为该两时刻 的地表温度, $k$ 为谐波数.

本文仍以 $0.4-1.1 \mu \mathrm{m}$ 及 $8-12.5 \mu \mathrm{m}$ 的入射、反射、发射的辐射代替太阳和地物的全波段

本文 1990 年 5 月 22 日收到. 
辐射.

$$
R_{n i}-S\left(1-\rho_{i}\right)-\varepsilon \sigma T_{i j}^{i}+\varepsilon \sigma T_{i k}^{i},
$$

式中 $\rho_{i}$ 是第 $j$ 个象元点的反射率, $T_{0 i}$ 是第 $j$ 象元点的地表温度. 显热通量为

$$
\begin{gathered}
H_{i}-\rho C_{p}\left(T_{0 i}-T_{0}\right) / r_{0}, \\
r_{0}-\frac{1}{0.16 u} \ln ^{2}\left(\frac{Z-d}{z_{0}}\right)\left(\frac{1-2 n(z-d) \cdot\left(T_{0}-T_{0}\right)}{\left(T_{0}+T_{0}\right) u^{2}}\right),
\end{gathered}
$$

其中 $u$ 为高度 $z$ 处的风速, $d$ 为植被的抬高层高度, $z_{0}$ 为地表粗粘度, $n$ 为经验常数, $n$ 值与 稳定度有关.

我们认为显热通量的最重要因子是地表温度, 它通过地气温度梯度及温度层结的两种作 用控制着显热通量的输送. 现近似假设在农耕区, 下垫面的粗䊁度及风速差异并不很大的前 提下,地表温度差异是构成显热输送差异的主要因子. 因此在一幅热象图中,任何一个象元点 与干点之间的显热通量比 $\zeta_{j}$ 有如下表达式:

$$
\begin{gathered}
\zeta_{i}=\left[\frac{\left(T_{0 j}-T_{a}\right)\left(1-\frac{2 n(z-d)}{u^{2}} \frac{T_{d r}-T_{a}}{T_{0 d r}+T_{0}}\right)}{\left(T_{0 d r}-T_{a}\right)\left(1-\frac{2 n(z-d)}{u^{2}} \frac{T_{0 j}-T_{a}}{T_{0 i}+T_{a}}\right)}\right]^{-1} \\
H_{i}=\zeta H_{d r},
\end{gathered}
$$

其中 $T_{0 d r}$ 为干点的地表温度.

地表潜热通量由热力、携带及供水三个因子控制, 前两个因子通常以蒸发力 $E_{0}$ 表示. 充 分湿润的短草地、浅水体的蒸发值接近蒸发力. 不充分供水的土壤水分蒸发不仅与当地的蒸 发力有关, 而且与土壤水分含量有关. 这是所谓供水因子. 从土壤含水的调艾系数到田间持 水量, 蒸发速率分两个阶段, 且均是线性关系. 约在 $15 \%$ 的土壤含水要为临界点. 为了简化, 近 似地用下式表示:

$$
E_{i}-\frac{W_{i}-W_{\theta}}{W_{i}-W_{\theta}} E_{0},
$$

式中 $W_{i}$ 为每个象元点的土壤水分含量, $W, W_{i}$ 分别为某一种土㙥类型的土墒水分调萎系数 及田间持水量。

土壤的热惯量与土壤含水量有密切关系. 土壤的热惯量又是由土壤、水和空气三者的热 惯的加权线性迭加,由下式表示:

$$
P_{r T}=\frac{V_{s} P_{s}+V_{W} P_{W}+V_{A} P_{A}}{V_{S}+V_{W}+V_{A}}
$$

式中 $P_{s} 、 P_{W} 、 P_{A} 、 P_{T}$ 分别为土壤、水、空气及总体的热惯量, $V_{s} 、 V_{W} 、 V_{A}$ 分别为土壤、水、空 气的容积. 在实验室里可以精确地测定土壤水分与热惯量的函数关系. 水的热惯屋通常要比 干土(无空隙)的热惯量大 10 倍左右,比空气的大三个数量级,水和空气在体积、热惯兵的互补 现象不明显, 因此湿土的热惯量的变化主要取决于土壤含水量的多少. 两者的关系近似地可 用线性方程表达:

$$
\begin{gathered}
W_{i}-a \cdot P_{1}-b, \\
E_{i}=\frac{a \cdot P_{i}-b-W_{\theta}}{W_{i}-W_{\theta}},
\end{gathered}
$$

象 12 朝

科学 通报 
由(10)-(14)式,每个象元点的热惯量

$$
\begin{aligned}
& P_{i}=\frac{\sum_{i=L_{1}}^{h_{2}}\left(R_{a i i}-\zeta_{i} H_{d r}+\frac{W_{\theta}-b}{W_{f}-W_{\theta}} L E_{0}\right) \Delta i}{\sqrt{t_{2}-t_{1}}\left(T_{0 i 2}-T_{0 i 1}\right)+\sum_{i=t}^{i_{2}} \frac{a L E_{0}}{W_{f}-W_{H}} \cdot \Delta i} . \\
& \text { 二、试验设计 }
\end{aligned}
$$

为了确认本文所提出的热惯模式的实用性及其验算土壤水分含量的精度. 我们除了在 定位遦感试验场作反复的模拟试验外, 还在多次航空遥感中进行验证. 这次试验是在广西全 州附近进行的, 时间在 1988 年 11 月 3-4 日, 正值水稻收割季节, 大部分农田已变成近于裸 地的稻茬地, 适合热惯量遥感。

航空遥感仪器是上海技术物理研究所的多光谱扫描仪, 波段范围分 $0.45-0.54 、 0.6-0.7$ 、 $0.8-0.9 、 10-12.5 \mu \mathrm{m}$ 四个波段. 热红外还进行夜航. 在全州以西约 $20 \mathrm{~km}$ 处为第一航道. 在 20 多公里的航道上设置 10 个观测点作同步观测. 用 SE590 列阵式光谱仪作准同步观测. 0.4$1.1 \mu \mathrm{m}$ 共 256 个波段, 测量出各种地物光谱曲线, 可以与航空多光谱扫描仪的波段作匹配组 合. 空地同步时相差最多不超过 2h. 热红外波段以 ER-2007 红外测温仪进行绝对同步观测. 由于仪器与人力的限制, 我们的设计用两台红外测温仪作同步观测的方法, 一台对典型地物的 温度的时间变化过程观测，另一台载于野外考察车沿 10 个同步观测点巡迴检测. 每一观测点 观测时间与飞机过程时间的差值, 由另一台红外测温仪所测量的温度过程曲线外延, 伐出修正 值, 每次测量时, 红外测温仪以标准的黑体源进行标定. 同时以同样的测温仪观测 4 个高度角 $\left(90^{\circ} 、 60^{\circ} 、 45^{\circ} 、 37^{\circ}\right)$ 的天空温度. 在红外测温的同时, 还观测通风干湿表温度、风速及净辐射 通量, 以取土称重法在 10 个同步观测点观测 $0-20 \mathrm{~cm}$ 土壤含水量.

资料(五个波段)先进行几何校正达到可以相互配准. 图象处理是以 IBM-FG100 系统进 行的.

\section{三、资料处理与试验结果分析}

首先将可见光, 近红外的三幅图象及白天和午夜的两幅热红外图象的灰度与地面定标的 反射率及地表温度值, 找出统计的函数关系, 其表达式如下:

$$
\begin{aligned}
& \rho_{1}=0.0248+0.000256 D_{1}, \\
& \rho_{2}=0.0618+0.000496 D_{2}, \\
& \rho_{3}=0.0734+0.00116 D_{3}, \\
& T_{d}=16.58+0.034 D_{4}, \\
& T_{\text {. }}-7.486+0.017 D_{i} .
\end{aligned}
$$

在本模式中, 以湿点的蒸发潜热值和干点的湍流显热通量值进行定标是提高估算精度的 重要步骤. 湿点定标在浅水体上进行, 水深仅 $0.5-1.2 \mathrm{~m}$.

$$
L E_{0}-R_{0}-\frac{\rho C}{r_{0}}\left(T_{0}-T_{0}\right),
$$

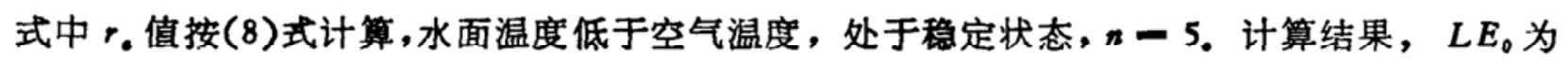
$502.4 \mathrm{Wm}^{-2}$, 相当于每小时蒸发 $0.7 \mathrm{~mm}$ 水. 干点选在附近最干的裸地, 土壤湿度为 $8.9 \%$, 接 


\section{近调菱系数.}

$$
H_{d r}-\frac{\rho C_{p}}{r_{c}}\left(T_{0 d r}-T_{c}\right),
$$

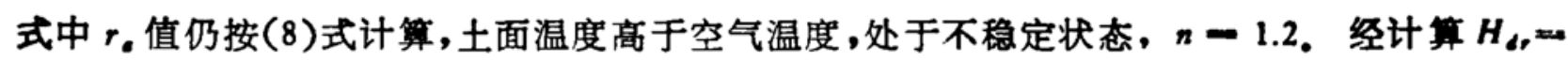
$65 \mathrm{Wm}^{-2}$.

说明一点,计算中 (8)式的 $n$ 值均取 1.2. 这是因为除水体以外,均处于不稳定状态, 而水 体的显热可以直接算出, 不影响精度.

按 (15)式可以直接算出热惯量值. 再由(13)式推算出土壤水分含量. 由于热传量值与土 壤水分含量是线性关系, 在上计算机计算时, 由(13)式代人(15)式,再扩大 100 倍, 直接得出土 壤含水量的百分比值. (13)与(15)式中的 $a, b$ 值是一致的, $a-2.01, b=0.01$.

在图象处理过程中找到同步观测点的位置, 查出的土壤水分含量与实测土壤水分含量对

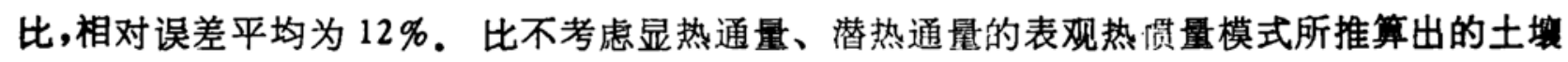
水分含量,精度提高 $8 \%$ 左右（见表 3 ).

婊 3 两种模式的抽样相对误差(广西全州)

\begin{tabular}{|c|c|c|c|c|c|}
\hline \multirow{2}{*}{ 测点地名 } & \multicolumn{3}{|c|}{ 土壤水分含艘(\%) } & \multicolumn{2}{|c|}{ 相对误荎(\%) } \\
\hline & 实测值 & $\begin{array}{l}\text { 表观热儤量 } \\
\text { 模式计算值 }\end{array}$ & $\begin{array}{l}\text { 改进热惯量 } \\
\text { 模式计算值 }\end{array}$ & 表观热顷畠模式 & 改进楱式 \\
\hline 广西岩附中西 & 15.3 & 18.0 & 16.2 & 18 & 13 \\
\hline 井水铺北 & 9.9 & 13.0 & 10.9 & 30 & 10 \\
\hline 地土地堂南 & 18.5 & 14.7 & 16.2 & 20 & 12 \\
\hline 岩泉南 & 17.7 & 20.8 & 19.6 & 17 & 10 \\
\hline
\end{tabular}

本文是对表观热惯量的改进．表观热惯量模式实质上是把太阳短波人射辐射作为土壤热 通量. 这显然对热惯量的估算造成很大误差, 因此考虑显热、潜热通辠的影响是提高遥感热惯 精度的关键. 然而热量平衡分量量级分析也至为重要. 本模式适用于裸地, 其土壤热通量可 达净辐射的 $30 \%$ 左右 (晴天中午). 由于遥感方法估算潜热、显热通量有一定误差. 当有植被 覆盖时土壤热通量降至 $10 \%$ 以下, 即使从植被表面温度推算出地表温度, 也不能用此模式。

\section{参考文䏻}

[1] Watson, K. et al., Proc. 7th Int. Symp. Remote ienstng Environ, 3(1071). 2017-2041.

[2] Pohn. H.A. et al., J Res. U.S. Geol. Surv., 2(1974), 147-158.

[3] Idso. S.B. et al.. J Appl. Meteorol., 15(1976), 811-817.

14 Carlson. T. N., J. Appl. Meteurol 20(1981), 67-87.

(5) Kahle. A.B.. J. Geophys. Res., 82(1977), 1673-1680.

(6) Price. J. C.. J. Geophys. Res.. 62(1977), 2582-2590.

171 Zheng Renhua, Symposium Proceedings of The 14th International Sympostum on Remore Sensing of Enviroment, 1980, 4.

[8]张仁华,地理学䧟感技术应用论文集, 1987 .

（9]张仁华,农田能量和水分研究, 1989 . 